\title{
Pelatihan Penyusunan Soal-Soal Berbasis HOTS dan Aplikasinya dalam Pembelajaran Daring di Sekolah Dasar
}

\author{
Andarini Permata Cahyaningtyas*, Yunita Sari, Sari Yustiana, Jupriyanto \\ Prodi Pendidikan Guru Sekolah Dasar, Fakultas Keguruan dan Ilmu Pendidikan, \\ Universitas Islam Sultan Agung, Semarang, Indonesia \\ *Corresponding Author \\ Jl. Kaligawe Raya KM.4, Terboyo Kulon, Genuk, Semarang - 50112 \\ E-mail: andarinipermata@ unissula.ac.id \\ Received: Revised: Accepted: Published: \\ 10 September 20203 December 202015 December 202025 December 2020
}

\begin{abstract}
Abstrak
Mitra dalam pengabdian masyarakat ini adalah SD Negeri Bangetayu Wetan 01, Genuk, Kota Semarang. Permasalahan yang dialami SD mitra adalah bahwa guru-guru kelas di SD Negeri Bangetayu Wetan 01 masih mengalami kesulitan dalam menyusun soal-soal berbasis HOTS dan bagaimana mengaplikasikannya dalam penilaian daring selama pandemi ini. Target luaran dalam PKM ini adalah bahwa: (1) terselenggaranya pelatihan penyusunan soal-soal berbasis HOTS dan aplikasinya dalam pembelajaran daring bagi guru SDN Bangetayu Wetan 01 Semarang; (2) mengembangkan kemampuan guru-guru di SDN Bangetayu Wetan 01 dalam menyusun soal-soal berbasis HOTS; dan (3) mengembangkan kemampuan guru-guru di SD Bangetayu Wetan 01 dalam membuat kuis daring sebagai sarana penilaian hasil belajar kognitif siswa. Metode yang digunakan dalam PKM ini adalah dengan metode ceramah, tanya jawab, dan praktik. Kemudian, setelah selesai mempraktikkan, guru dievaluasi apakah penilaian daring yang telah dibuat dapat berfungsi secara optimal. Hasil menunjukkan bahwa semua guru telah mampu menyusun soal-soal berbasis HOTS dan mengaplikasikannya dalam kuis daring menggunakan Quizizz.
\end{abstract}

Kata kunci: HOTS; penilaian kognitif; penilaian daring; pembelajaran daring; Quizizz

\begin{abstract}
The partner in this community service is SDN Bangetayu Wetan 01, Genuk, Semarang. The problems are that the teachers still experience difficulties to arrange HOTS-based questions and how they should implement it by using online assignment in this pandemic season. The output of this community service are: (1) the implementation of HOTS-based question arrangement training for teachers of SDN Bangetayu Wetan 01 ; (2) teachers of SDN Bangetayu Wetan 01 can compile HOTS-based questions; and (3) teachers of SDN Bangetayu Wetan 01 can create an online assessment to get result from student work. The methods used in this activity were lecturing, question and answer, and practice method. After practicing, the online assessment created by the teacher was evaluated whether it can be used optimally or not. The result showed that all teachers have been able to compile HOTS-based question and applied it in an online assessment by using Quizziz.
\end{abstract}

Keywords: HOTS; cognitive assessment; online assessment; online learning; Quizizz 


\section{PENDAHULUAN}

Kurikulum 2013 menjadi kurikulum yang berlaku di Indonesia saat ini. Kurikulum 2013 mengalami beberapa kali revisi baik dalam muatan pelaksanaan pembelajaran dan evaluasinya. Salah satu tujuan diselenggarakannya Kurikulum 2013 adalah untuk memupuk nilai, sikap, dan karakter sehingga karakter positif siswa akan terbentuk secara bertahap (Muhammad \& Saparahayuningsih, 2016). Revisi terakhir dilakukan pada Kurikulum 2013 pada tahun 2017 adalah menambahkan adanya muatan HOTS dalam proses pembelajaran dan penilaiannya. HOTS merupakan singkatan dari Higher Order Thinking Skills atau keterampilan berpikir tingkat tinggi.

HOTS memiliki tahapan yang meliputi menganalisis, mengevaluasi, dan mencipta. Dalam menganalisis, ada tiga keterampilan yang harus dikuasai siswa, yakni membedakan, mengorganisasi, dan mengasosiasikan. Sementara itu, evaluasi mencakup keterampilan menilik kembali dan mengkritisi. Terakhir, mencipta melibatkan keterampilan memformulasikan, merencanakan, dan memproduksi atau mengonstruksi (Krathwohl, 2002). Ketiga tahapan tersebut merupakan tiga tingkatan teratas dari Revisi Taksonomi Bloom yang dilakukan oleh Anderson dan Krathwohl pada tahun 2001. Pembelajaran dan evaluasi dalam Kurikulum 2013 diarahkan pada kegiatan dan keilmuan untuk mencapai ketiga tingkatan tersebut. Siswa digiring untuk tidak hanya mengingat, memahami, dan menerapkan yang masih dalam tingkatan LOTS (Lower Order Thinking Skill) atau keterampilan berpikir tingkat rendah (Nugroho, 2018).

Oleh karena itu, guru-guru juga harus mampu menciptakan penilaian yang sejalan dengan pembelajaran yang bermuata HOTS karena pembelajaran berbasis HOTS akan dapat tercapai hanya jika guru merencanakan, mengimplementasikan, dan mengevaluasi pembelajaran yang berfokus pada keterampilan berpikir tinggat tinggi siswa (Sudjiono, 2013). Namun pada kenyataannya, guru-guru sekolah dasar merasakan bahwa mendesain penilaian berbasis HOTS adalah hal yang sulit dan mereka juga tidak memahami bagaimana mengaplikasikan penilaian tersebut kepada siswa-siswa mereka (Okayana, Suntoro, Sabdaningtyas, \& Darsono, 2019; Suratmi, Laihat, Asnimar, \& Handini, 2020). Padahal, penilaian dirancang agar siswa dapat secara aktif terlibat dan terikat dengan proses pembelajaran (Dewi, 2008). Untuk itulah, guruguru semakin memiliki alasan kuat untuk dapat menyusun penilaian berbasis HOTS yang dapat diimplementasikan pada siswa, khususnya dalam masa pandemi Covid-19 yang memaksa mereka untuk belajar dari rumah. Jika masih merasa kesulitan pun, buku tentang instrumen penilaian berbasis HOTS juga dapat bermanfaat bagi guru sebagai panduan untuk menyusun soal-soal HOTS secara mandiri (Cahyaningtyas, 2020).

Pembelajaran daring pada dasarnya menjadi bentuk transformasi cara berpikir manusia dalam berkomunikasi dan berkolabirasi (Garisson, 2017). Pembelajaran dengan model ini dapat dilakukan dengan 3 cara, yakni dengan self-paced independent study, asynchronous interactive, dan synchronous interactive (Kattoua, Al-Lozi, \& Alrowwad, 2016). Dalam self-paced independent study, guru sudah mempersiapkan materi untuk jangka waktu tertentu termasuk di dalamnya ada materi dan evaluasi yang telah disertai dengan kunci jawaban dan pedoman penilaian. Hal ini membuat siswa lebih mandiri dalam menentukan jadwal belajarnya sendiri, namun tidak ada interaksi antara siswa dan guru secara langsung. Sementara itu, dalam asynchronous interactive, siswa dan guru melakukan interaksi namun tidak secara langsung dan tidak dalam waktu yang bersamaan. Guru dapat menggunakan layanan surel atau chat untuk membagikan materi atau soal-soal evaluasi yang dapat dikerjakan siswa dalam kurun waktu tertentu, dan dapat pula bertanya jawab dengan balasan sesuai dengan waktu luang yang dimiliki oleh siswa dan guru. Berbeda lagi dengan synchronous interactive, di mana siswa dan guru melakukan tanya jawab dan pembahasan materi serta soal-soal evaluasi dalam waktu yang sama. 
Hanya saja ada beberapa kendala yang dapat dialami oleh guru dan siswa selama melakukan pembelajaran daring secara synchronous interactive, seperti koneksi internet yang lambat sehingga siswa tidak bisa memberikan umpan balik terhadap materi dan soal evaluasi yang diberikan guru, siswa belum memahami penggunaan aplikasi daring atau siswa membutuhkan waktu yang lebih daripada teman-teman lain sehingga tertinggal dari temantemannya (Manhas, 2017). Kendala ini membuat guru harus memiliki alternatif yang dapat dilakukan untuk melakukan penilaian kognitif apabila kondisi siswa di kelas tersebut berbedabeda.

SD Negeri Bangetayu Wetan 01 adalah salah satu SD yang termasuk memiliki kebutuhan dalam menyusun soal-soal bermuatan HOTS dan penerapannya dalam penilaian berbasis daring selama pandemi ini. Ada 12 orang guru kelas di SD Negeri Bangetayu Wetan 01 yang mengajar di kelas 1 sampai 6. Guru-guru kelas tersebut masih merasa kesulitan untuk menggali kemampuan menganalisis, mengevaluasi, dan mencipta siswa. Penilaian pembelajaran dilakukan sebatas pengungkapan kemampuan mengingat, memahami, dan menerapkan atau hanya sebatas pada LOTS. Penilaian yang belum mampu mengukur HOTS berarti belum sepenuhnya dapat mengukur pencapaian pembelajaran di Kurikulum 2013.

Selain itu, program belajar di rumah juga membuat siswa harus belajar dari rumah. Guru harus mengubah proses pembelajaran yang awalnya tatap muka menjadi pembelajaran daring. Hal ini juga cukup menyulitkan guru dalam melakukan penilaian terhadap siswa yang terpisah oleh jarak dan berbedanya kondisi yang dialami siswa yang satu dan lainnya. Oleh karena itu, perlu diadakannya pelatihan terhadap guru-guru di SD Negeri Bangetayu Wetan 01 dalam menyusun soal-soal bermuatan HOTS dan bagaimana mengimplementasikannya dalam penilaian daring sehingga evaluasi dapat tetap berjalan meski siswa harus belajar dari rumah.

\section{METODE}

Pelaksanaan pelatihan penyusunan soal-soal berbasis HOTS dilakukan dengan beberapa metode secara bersama-sama, seperti metode ceramah, tanya jawab, dan praktik. Metode ceramah diterapkan untuk mengemukakan teori terkait variabel, dan metode tanya jawab dilakukan bersamaan dengan penyampaian materi untuk meminimalisasi kekurangpahaman yang dialami oleh guru selama materi dijelaskan. Sementara itu, metode praktik akan dilakukan setelah konsep dipahami agar keterampilan menyusun soal-soal berbasis HOTS dan membuat penilaian daring dengan menggunakan web atau aplikasi tertentu.

\section{HASIL DAN PEMBAHASAN}

SDN Bangetayu Wetan 01 merupakan salah satu sekolah yang berada di satu kecamatan dengan Universitas Islam Sultan Agung. Sejak tahun 2016, SDN Bangetayu Wetan 01 telah menjadi sekolah mitra Prodi PGSD FKIP Unissula. Oleh karena itu, ketika diketahui bahwa SDN Bangetayu Wetan 01 memiliki kebutuhan pelatihan tentang HOTS dan penilaian daring, pengabdian ini ditujukan pada sekolah tersebut. Pelatihan ini dilakukan pada minggu keempat bulan Agustus selama 32 jam dengan rincian teori tatap muka selama 6 jam, praktik selama 24 jam.

\section{Wawancara awal}

Wawancara awal dilakukan untuk mengetahui kebutuhan sekolah dengan Kepala Sekolah SD Bangetayu Wetan 01. Dari hasil wawancara awal tersebut, diketahui bahwa guru-guru SDN Bangetayu Wetan 01 membutuhkan pelatihan dalam hal penyusunan soal HOTS. Selain itu, 
mengingat saat ini pembelajaran daring menjadi hal baru bagi pendidikan sekolah dasar, Kepala Sekolah SDN Bangetayu Wetan 01 juga menghendaki adanya pelatihan yang dapat menunjang kinerja guru dalam melakukan pembelajaran daring. Oleh karena itu, akhirnya disepakati bahwa pelatihan yang akan dilakukan adalah pelatihan penyusunan soal-soal berbasis HOTS dan implementasinya dalam pembelajaran daring khususnya yang dikemas dalam bentuk kuis.

\section{Perencanaan}

Setelah mengetahui kebutuhan guru-guru SDN Bangetayu Wetan 01, perencanaan dilakukan untuk menentukan materi apa yang akan disampaikan dalam pelatihan tersebut sekaligus pembagian alokasi waktu untuk tiap materinya. Pelatihan implementasi pemberian soal secara daring akan menspesifikkan dengan menggunakan Quizziz sebagai sarananya. Quizizz dipilih karena mudah untuk dibuat; guru-guru tidak perlu menginstal aplikasi karena dapat langsung membuatnya melalui website quizizz.com; dan hanya membutuhkan ponsel pintar untuk membuat, membagikan link, serta melihat hasilnya.

Selanjutnya, mengingat kondisi masih belum memungkinkan untuk berkumpul dalam jumlah banyak dan dalam waktu yang lama, akhirnya pelatihan ini dibagi menjadi sesi luring dan daring. Sesi luring adalah untuk menjelaskan teori, serta mendemonstrasikan dan mempraktikkan langkah-langkah penyusunan soal berbasis HOTS sekaligus pengoperasian Quizizz secara kelompok; sedangkan sesi daring adalah untuk praktik individual dan konsultasi melalui email dan chat whatsapp.

\section{Pemberian materi dan praktik tentang penyusunan soal berbasis HOTS}

Pemberian materi dan praktik penyusunan soal HOTS dilakukan pada tanggal 25 Agustus 2020 pukul 08.00 hingga 15.00. Pemateri pertama memberikan teori tentang HOTS dan penilaian berbasis HOTS bagi siswa sekolah dasar. Materi dimulai dengan pembukaan yang dilakukan oleh MC dan dilanjutkan dengan sambutan kepala sekolah. Setelah itu, MC memperkenalkan para narasumber yang tergabung dalam pelaksanaan pengabdian masyarakat kali ini. Untuk lebih mencairkan suasana, guru-guru diajak untuk melakukan ice breaking sehingga konsentrasi mereka akan meningkat dan lebih siap dalam menerima materi pelatihan.

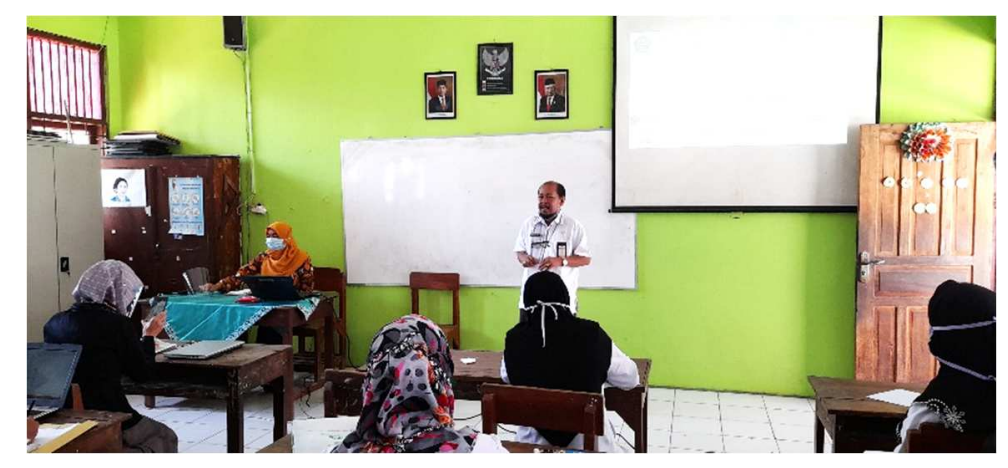

Gambar 1. Kepala Sekolah memberikan sambutan

Selanjutnya, tujuan pelaksanaan pengabdian masyarakat disampaikan oleh MC sebelum selanjutnya kesempatan diberikan pada narasumber untuk memulai sesi inti dari pelatihan hari itu. Teori mengenai HOTS yang disampaikan dengan metode ceramah membuka materi pelatihan hari ini. Dimulai dari penjelasan mengenai apa saja keterampilan yang teribat di dalam HOTS, serta bagaimana mengembangkan materi berbasis HOTS tersebut ke dalam soal-soal 


\section{Indonesian Journal of Community Services}

Volume 2, No. 2, November 2020

http://jurnal.unissula.ac.id/index.php/ijocs

DOI: http://dx.doi.org/10.30659/ijocs.2.2.162-171

evaluasi. Tanya jawab dilakukan tanpa ada sesi khusus, tapi berlangsung secara natural selama materi diberikan. Interaksi dilakukan oleh narasumber dan guru agar pelatihan lebih hidup dan guru-guru juga aktif memberikan umpan balik terhadap materi yang diberikan. Diskusi tentang permasalahan yang dihadapi oleh guru-guru juga dilakukan agar solusi dapat ditemukan secara bersama-sama melalui diskusi terbuka tersebut.

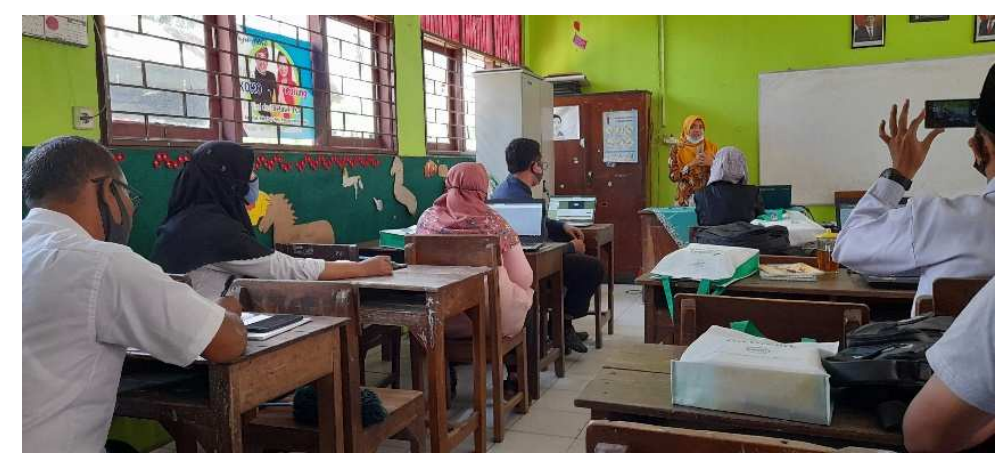

Gambar 2. Pemberian materi tentang HOTS

Selanjutnya, setelah materi selesai diberikan, pelatihan beralih pada praktik penyusunan soal-soal berbasis HOTS yang dipandu oleh narasumber utama dan dibantu oleh narasumber lainnya. Guru-guru mempersiapkan materi bermuatan HOTS yang akan diberikan pada siswa sesuai dengan kelas atau mata pelajaran yang diampu.

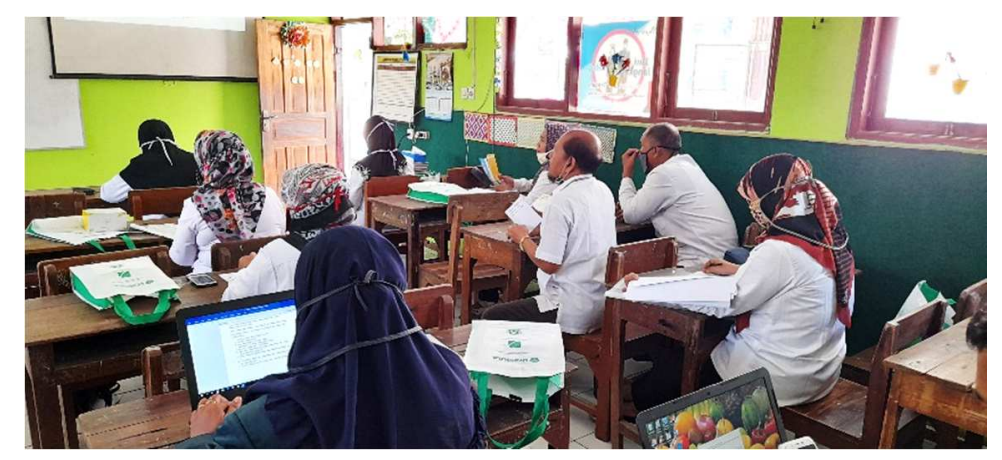

Gambar 3. Praktik penyusunan soal HOTS

Praktik dilaksanakan secara berkelompok berdasarkan kelas atau mata pelajaran yang diampu. Praktik berlangsung secara aktif dan guru-guru tampak antusias dalam menyusun soalsoal yang didasarkan pada buku tema sesuai dengan kelas yang diampu dengan mengacu pada subtema tertentu yang ingin guru-guru berikan kepada siswa pada semester 1 ini. Dengan bantuan tim pengabdian, seluruh pertanyaan dari guru-guru terkait dengan penyusunan soal-soal berbasis HOTS dapat terakomodasi dengan baik. Berikut adalah contoh soal yang dibuat oleh guru. 
1. Perhatikan gambar rantai makanan berikut!

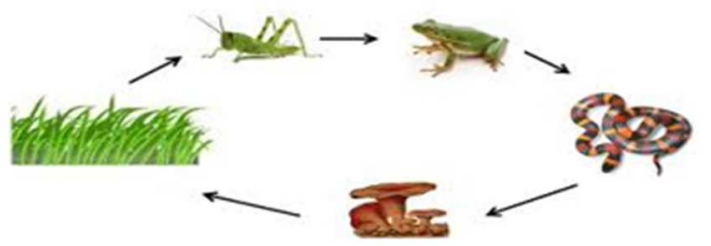

Berdasarkan gambar di atas, pernyataan yang paling tepat menggambarkan kondisi rantai makanan jika katak mengalami kepunahan adalah

a. Belalang menjadi berkurang

b. Ular sawah bertambah banyak

c. Retani mengalami gagal panen

d. Ranen padi menjadi melimpah

2. Empat orang peserta didik yang berbama Andi, Bekti. Caca dan Dina menyelidiki apakah tanaman membutuhkan cahaya untuk bertahan hidup. Mereka masing masing menanam tanaman yang sama dengan kondisi yang berbeda.

Andi semua tanaman disimpan dalam keadaan gelap sepanjang waktu

Bekti: sebagian tanaman disimpan dalam gelap sepanjang waktu

Caca:semua tanaman disimpan dalam cahaya normal disiang hari

Dina sebagian tanaman disimpan dalam cahaya normal siang hari

Dari keterangan di atas, peserta didik yang melakukan percobaan dengan kondisi yang paling tepat ialah,

a. Andi

b. Bekti

c. Caca

d. Dina

Gambar 4. Contoh soal HOTS yang disusun oleh guru

Dalam menyusun soal-soal tersebut, guru-guru mengalami kendala dalam memilih kata kerja operasional yang sesuai bagi soal pilihan ganda, serta membuat pilihan jawaban yang mengarahkan siswa untuk dapat berpikir tingkat tinggi. Kendala tersebut dapat diatasi dengan adanya kerja sama antarguru dan bantuan dari pemateri. Setelah selesai praktik kelompok, guruguru memiliki kesempatan untuk melakukan praktik individual di rumah dan melakukan konsultasi secara online via email dengan narasumber dan tim pengabdian.

\section{Pemberian Materi dan Praktik tentang Penilaian Daring}

Pertemuan ke-2 dilakukan pada tanggal 26 Agustus 2020 juga pada pukul 08.00 hingga 15.00. Pemateri kedua memberikan teori tentang pembelajaran daring dan macam-macam aplikasi yang dapat digunakan untuk melakukan penilaian daring, seperti Google Form, Kahoot, Quizizz, Mentimeter, dan lain-lain. Seperti pada pertemuan pertama, materi dimulai dengan pembukaan yang dilakukan oleh MC namun kali ini tidak ada dengan sambutan kepala sekolah. Setelah itu, materi tentang pembelajaran dan penilaian daring disampaikan kepada guru-guru dengan bantuan slide presentasi. Dalam pemaparan dijelaskan tentang kelebihan dan kekurangan yang dimiliki oleh masing-masing kategori pembelajaran daring yang dapat diimplementasikan oleh guru. Selain itu, jenis aplikasi pembelajaran dan penilaian/kuis daring juga dipaparkan agar guru memiliki banyak referensi untuk dapat dipilih sesuai dengan kebutuhan. 


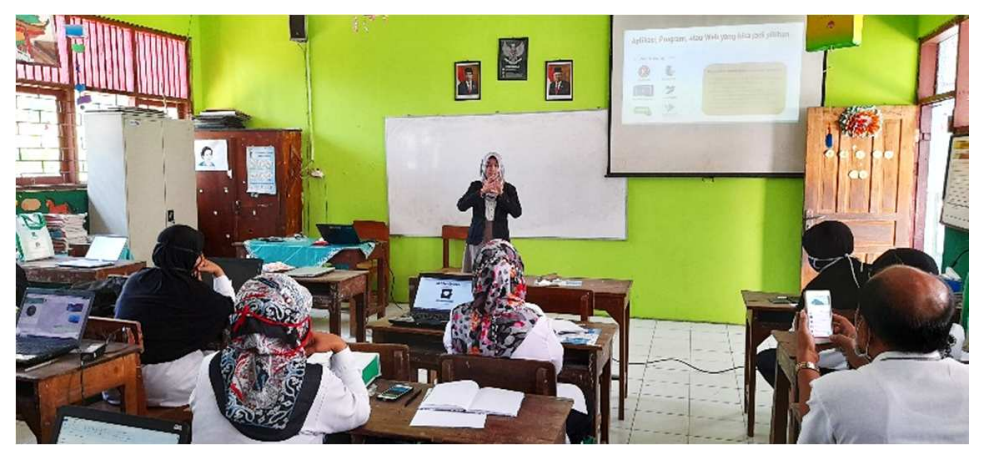

Gambar 5. Pemberian materi tentang kuis daring

Setelah melalui tanya jawab dengan guru mengenai jenis-jenis penilaian daring yang memungkinkan untuk dilakukan, guru-guru diajak untuk melakukan evaluasi terhadap materi menggunakan Quizizz yang telah disiapkan oleh narasumber sebelumnya. Melalui kuis ini, guru diberi kesempatan untuk mencoba langsung dan merasakan bagaimana mengerjakan soal-soal menggunakan Quizizz ini secara berkelompok. Kelompok dibuat berdasarkan kelas yang diampu. Quizizz dipilih karena tidak memerlukan aplikasi khusus dan dapat langsung masuk melalui alamat website quizizz.com. Selain itu, peringkat peserta kuis dapat langsung dilihat setelah setiap nomor selesai dijawab. Penskoran Quizizz dilakukan dengan sistem siapa cepat dan benar dia yang menang, sehingga timbullah semangat berkompetisi di kalangan peserta kuis. Saat kuis berlangsung, guru-guru terlihat sangat antusias untuk berlomba menjadi juara satu. Guru-guru pun dapat melihat hasil serta kunci jawaban dari pertanyaan yang telah dijawab sebagai bahan evaluasi individual. Pelaksanaan kuis ini sangat menarik minat guru untuk belajar membuat kuis yang serupa sebagai sarana penilaian bagi ketercapaian hasil belajar siswa.

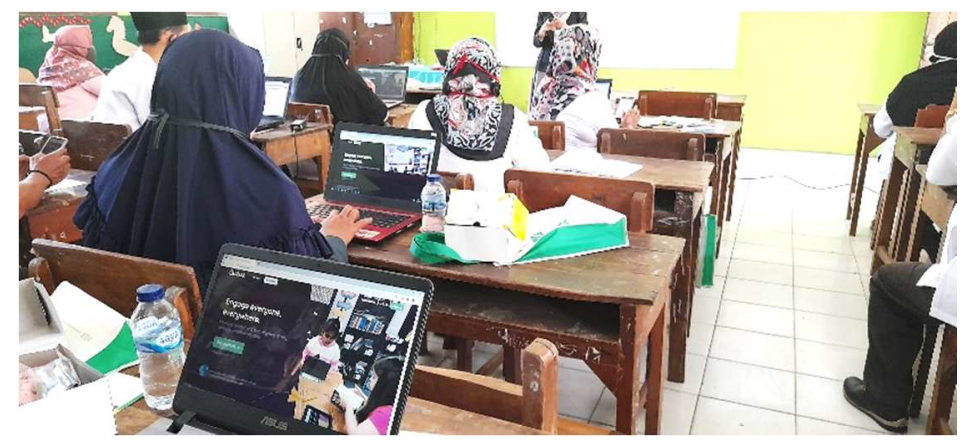

Gambar 6. Guru-guru mulai mempraktikkan untuk membuat kuis daring 


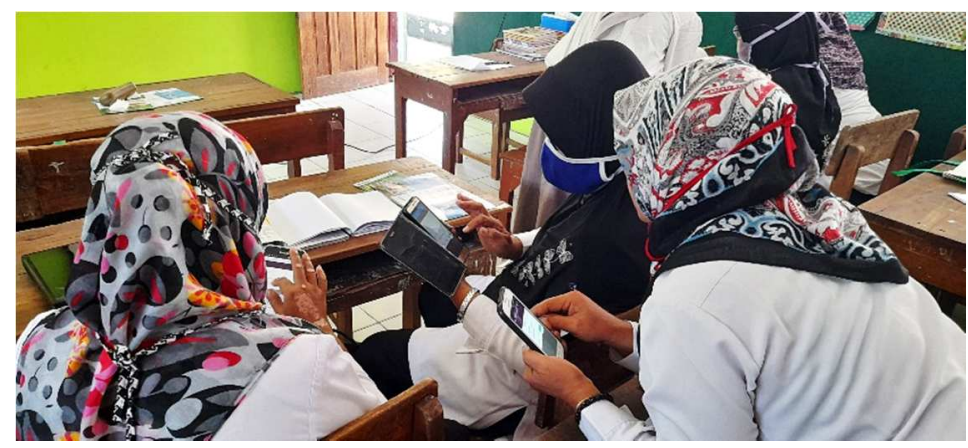

Gambar 7. Guru-guru saling membantu dalam membuat kuis daring

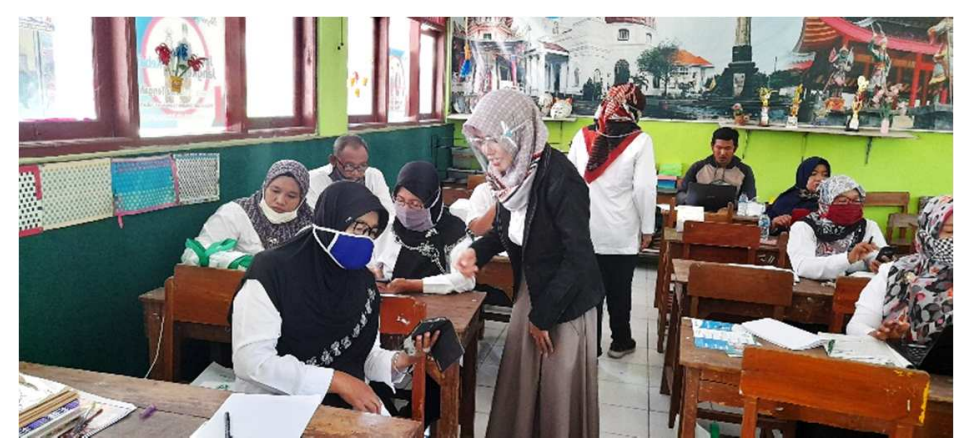

Gambar 8. Pemateri membantu guru-guru dalam membuat kuis daring

Beberapa kendala yang dialami guru biasanya berhubungan dengan kondisi ponsel yang sudah cukup lama sehingga membutuhkan waktu untuk dapat memproses tindakan, kemudian juga sinyal wifi sekolah yang naik turun membuat guru-guru harus beberapa kali me-refresh laman web agar dapat kembali lancar dalam membuat kuis. Namun, di luar kendala tersebut, guru-guru sangat aktif dan bersemangat dalam mengikuti pelatihan ini.

\section{Praktik Individual dan Konsultasi Daring}

Setelah dapat menyusun soal-soal berbasis HOTS dan menyusunnya pada Quizizz, guru-guru kemudian praktik secara individual di rumah. Guru dipersilakan untuk berkonsultasi dengan narasumber, termasuk untuk mengujicobakan kuis yang telah dibuat. Konsultasi ini dilaksanakan selama jam kerja melalui chat dan email. Bagi yang sudah mahir dan tidak membutuhkan konsultasi dipersilakan untuk langsungs aja mengirimkan link hasil pembuatan kuis yang berisi soal-soal HOTS sebagai tagihan akhir pelatihan.

\section{Evaluasi Kegiatan}

Dari hasil pelatihan ini, dapat diketahui bahwa 12 guru kelas dan 4 orang guru mapel telah berhasil menyusun soal-soal HOTS dan membagikannya dalam bentuk kuis daring kepada siswa. Oleh karena itu, dapat disimpulkan bahwa pelatihan ini telah berhasil. Namun ada beberapa hal yang menjadi catatan seperti menginformasikan kepada guru-guru agar mempersiapkan kuota apabila ada kendala dengan sinya wifi sekolah agar jika ke depannya ada pelatihan yang membutuhkan koneksi internet, guru-guru dapat dengan lancar mengikuti rangkaian acara. 


\section{KESIMPULAN}

Tujuan diadakannya pelatihan ini adalah untuk mengembangkan kemampuan guru-guru SDN Bangetayu Wetan 01 dalam menyusun soal-soal berbasis HOTS dan mengimplementasikannya dalam pembelajaran daring dalam bentuk kuis. Dari pelaksanaan pelatihan didapati bahwa guruguru merasa antusias dalam menyusun soal-soal HOTS dan bersemangat membuat kuis daring yang menarik bagi siswa dengan menggunaan Quizizz. Harapannya, hasil dari pelatihan ini akan membawa dampak baik bagi guru dan siswa di SDN Bangetayu Wetan 01 khususnya dalam menerapkan evaluasi daring selama pandemi ini.

\section{UCAPAN TERIMA KASIH}

Ucapan terima kasih kami berikan kepada Universitas Islam Sultan Agung yang telah memberikan izin dan peluang sehingga pelatihan ini dapat terwujud. Terima kasih juga ditujukan pada kepala sekolah dan guru SDN Bangetayu Wetan 01 yang telah bersedia bekerja sama sehingga pelatihan ini dapat berjalan dengan lancar.

\section{DAFTAR PUSTAKA}

Cahyaningtyas, A.P., Sari, Y., \& Pradana, A.B.A. (2020). High order thinking skills: How is it integrated with cognitive assessment?. Jurnal Ilmiah Pendidikan Dasar, Vol.7(2), 109120. DOI: $10.30659 /$ pendas.7.2.109-120.

Dewi, K.T. (2018). Developing assessment instrument based curriculum 2013 for teaching micro teaching in English education department of Undiksha. International Journal of Social Science and Humanities, Vol. 2 (3), 96-106. DOI: 10.29332/ijssh.v2n3.205.

Garrison, R. (2017). E-learning in the 21st Century: A Community of Inquiry Framework for Research and Practice (3rd Edition). New York: Routledge.

Kattoua, T., Al-Lozi, M., \& Alrowwad, A. (2016). A Review of Literature on E-Learning Systems in Higher Education. Journal of Business Management and Economic Research, Vol, $\quad 7 \quad$ (5), 754-762. Diakses dari https://www.researchgate.net/profile/Taghreed_Katoua/publication/309242990_A_Revie w_of_Literature_on_E-

Learning Systems in Higher Education/links/5807385108aeb85ac85f6893.pdf

Krathwohl, D.R. (2002). A revision of Bloom's Taxonomy: An Overview. Theory into Practice, Vol.41 (4), 212-218.

Manhas, P.S. (2017). Strategic e-learning models in brand building of educational institutions. Materials of the IV International correspondence (electronic) scientific conference dedicated to the 60th anniversary of the Faculty of Philology of BashSU. Diakses dari http://www.bashedu.ru/sites/default/files/niu/files/aktualnye-problemy-teoreticheskoy-iprikladnoy-filologii-2017-yubiley_0.pdf\#page=3

Muhamad, B., \& Saparahayuningsih. (2016). An attitude and character instructional development based on curriculum 2013 in elementary school. Creative Education, Vol. 7 (2), 269-277. DOI: 10.4236/ce.2016.72025.

Nugroho, A. (2018). HOTS: Higher order thinking skills. Jakarta: Grasindo. 
Okayana, K., Suntoro, I., Sabdaningtyas, L., \& Darsono. (2019). The development of higher order thinking skill-based assessment instrument for elementary school integrated thematic learning. Journal of Education and Practice, Vol. 10 (15). DOI: 10.7176/JEP.

Suratmi, Laihat, Asnimar, \& Handini, E.O. (2020). Teachers understanding of HOTS based assessment in elementary school. Proceeding of The 2nd International Conference on Elementary School, Vol.2 (1), 1157-1164. 